\title{
Pesca artesanal e manejo: conflito socioambiental em uma área de unidade de conservação do Parque Nacional do Cabo Orange, Oiapoque, Amapá
}

\section{Artisanal fisheries and management: environmental conflict in a protected area National Park Cabo Orange, Oiapoque, Amapá}

Uriens Maximiliano Ravena Cañete - Doutorando do Programa de Pós-Graduação em Sociologia e Antropologia (PPGSA), UFPA. E-mail: uriensmax@gmail.com

Voyner Ravena Cañete - Professora do Programa de Pós-Graduação em Sociologia e Antropologia - PPGSA/UFPA e do Programa de Pós-Graduação em Ecologia Aquática e Pesca (PPGEAP), UFPA. E-mail: ravenacanete@ufpa.br

Sônia Maria Simões Barbosa Magalhães Santos - Professora do Programa de Pós-Graduação em Gestão dos Recursos Naturais e Desenvolvimento Local (PPGEDAM), UFPA e Sociologia e Antropologia (PPGSA), UFPA. E-mail: smag@ufpa.br

\section{Resumo}

Este trabalho descreve como pescadores artesanais têm se ordenado política e ambientalmente no que se refere a cenários de conflito em águas costeiras por territórios de pesca. Descreve, especificamente, os conflitos pesqueiros ao redor do Parque Nacional do Cabo Orange, no município de Oiapoque, Amapá, ao norte do Brasil. Os parques nacionais são um modelo de unidade de conservação de proteção integral à natureza, não permitindo a presença humana ou exploração de seus recursos. Contudo, a partir da pressão originada pela demanda internacional e nacional de pescado e diante dos modos de sobrevivência de populações tradicionais que dependem da pesca, a Colônia de Pescadores Z-03 do município do Oiapoque, somada ao Estado, na figura do ICMBIO e outros atores e agentes sociais se articularam na busca de novos arranjos para o uso desses recursos naturais. Por meio de entrevistas e trabalho de campo marcado por observação direta, este ensaio descreve como no Oiapoque um termo de compromisso, estabelecido entre a Colônia de Pescadores Z-03, o ICMBIO e o Ministério Público, vem se mostrando parcialmente efetivo como uma estratégia e alternativa para o manejo de recursos pesqueiros, gestão de conflitos socioambientais e medida temporária para uma solução compensatória referente à população remanescente do Parque Nacional do Cabo Orange.

\section{Palavras-chave}

Termo de Compromisso. Recurso Pesqueiro. Conflito Socioambiental.

\begin{abstract}
This paper describes how artisanal fishermen have ordered politically and environmentally in conflict scenarios in coastal waters by fishing territories. Describes specifically the fisheries conflicts around the National Park Cabo Orange, in the municipality of Oiapoque, Amapá, north of Brazil. The National Parks are a model of strictly protected unit to nature, not allowing human presence or exploitation of its resources, however, from the pressure caused by the international and national demand for fish and before the traditional populations Survival modes dependent on fishing, the colony of fishermen in the city of Oiapoque, added to the State, in the figure of ICMBIO and other social actors and agents joined forces in the search for new arrangements for the use of these natural resources. Through interviews and field work marked by direct observation, this paper describes how in Oiapoque, a term of commitment signed between Cologne Fishermen, ICMBIO and the prosecutor, has proven partially effective as a strategy and alternative to the management of fishing resources, management of environmental conflicts and temporary measure to a compensatory solution concerning the remaining population of the National Park Cabo Orange.
\end{abstract}

\section{Keywords}

Statement of Commitment. Fishery Resource. Environmental Conflict. 


\section{INTRODUÇÃO ${ }^{1}$}

Os recursos pesqueiros são objeto de conflito no mundo, e no Brasil, esse quadro se repete e em especial na região amazônica (RUFFINO, 2005; ISAACNAHUM, 2006; FRÉDOU et al., 2010). Nesta, os conflitos pesqueiros se dão tanto em águas interiores, como é o caso da pesca em rio e lagos, como em águas oceânicas, que é o caso da costa norte brasileira (estados do Pará e do Amapá), área com notória variedade de espécies de pescado e marcada pela dependência da população tradicional dessa atividade (FRÉDOU et al., 2010).

Este trabalho trata da pesca artesanal ${ }^{2}$ na área da costa norte brasileira, especificamente na Unidade de Conservação (doravante UC) conhecida como Parque Nacional do Cabo Orange (doravante PNCO), município do Oiapoque, fronteira entre o Amapá e a Guiana Francesa. Tem por objetivo apresentar um cenário de conflito socioambiental que se estabelece após a implantação do PNCO. Neste, a pesca e o recurso pesqueiro figuram como atividade e recurso natural de disputa entre os agentes sociais inseridos nesse contexto. Este artigo faz ainda uma reconstituição história sobre o processo que engendrou o atual cenário de conflito pesqueiro no entorno do PNCO, dando ênfase às estratégias locais para a solução de tais conflitos. Para tanto, este ensaio está dividido em quatro seções. A primeira apresenta o cenário anterior à instituição do PNCO, dando especial destaque à disponibilidade e riqueza dos recursos pesqueiros acessados pela população que vivia no interior do Parque. Descreve, em seguida, o período entre os anos de 1980 e 2000, evidenciando o processo de criação do PNCO (enquanto uma área protegida marcada pelo modelo preservacionista ${ }^{3}$ ) e os conflitos gerados pela restrição do acesso e uso dos recursos

1 Este trabalho está inserido no projeto OSE Guyamapa - Observação por Satélite do meio ambiente sendo parcialmente financiado pelo Institut de Recherche pour le Développement.

2 A definição de pesca artesanal e industrial é discutível, especialmente para a Amazônia, pois quando comparada à outras regiões do país, onde embarcações industriais atingem tonelagens muito superiores às encontradas nessa região, com equipamentos sofisticados, essa definiç̧ão mostra sua fragilidade (ISAAC-NAHUM, 2006). No entanto, para este ensaio, estende-se pesca artesanal como aquela que utiliza mão de obra especialmente marcada por relações familiares ou de parentesco, ademais de serem desenvolvidas por embarcações com tonelagens que não ultrapassam o limite de 15 mil quilos. Tal descrição se embasa na própria definição dos pescadores entrevistados.

3 A proposta preservacionista, como cita Diegues (2001), vê a criação dos parques movida pela necessidade de "contemplação da natureza selvagem, lugar de reflexão e de isolamento espiritual (p.26)". Nessa proposta o homem encontra-se fora do cenário natural, como se ele mesmo resultasse de um processo exógeno à natureza, longe de se caracterizar enquanto um integrante ativo do ecossistema. Nesse modelo, o homem se distancia do contato e uso dos recursos naturais, pois a natureza está posta para contemplação e estudo da sociedade. Nesse sentido, os parques criados até meados da década de 1980, não contemplam a presença de populações que fazem uso de seu recurso. Em contraposição à abordagem preservacionista, evidencia-se o modelo conservacionista que prevê a presença humana nas áreas de conservação, já que as populações originárias dessas áreas funcionariam como controladores e fiscalizadores do acesso e uso dos recursos naturais (DIEGUES, 2001).

Novos Cadernos NAEA • v. 18 n. $3 \cdot$ p. 179-198 • set-dez. 2015 
naturais em seu interior. Ainda nesta segunda seção são descritos os relatos e percepções da população que residia no interior do Parque, sobre o processo de expropriação por ela vivido até desembocar em sua inserção na sede municipal da cidade de Oiapoque. A terceira e última seção trata do período entre 2000 e 2010, apresentando o conflito originado pela feroz inserção dos pescadores do estado do Pará em território amapaense, inserção marcada por atividades predatórias e autoritárias. Descreve, ainda, o período a partir do ano de 2012, onde a organização dos pescadores do município do Oiapoque instituiu, por meio da Colônia de Pescadores Z-3, do Instituto Brasileiro do Meio Ambiente e dos Recursos Naturais Renováveis (IBAMA) e do Ministério Público Federal (MP), um Termo de Compromisso como ferramenta de manejo e diminuição de conflito entre os diferentes agentes que acessam e usam o território pesqueiro no interior do PNCO.

\section{VILA DE TAPEREBÁ: A VIDA NO INTERIOR DO PNCO}

Esta seção apresenta a área do PNCO como uma área natural, rica em biodiversidade e com uma população específica que a ocupa, desenvolvendo práticas que refletem e caracterizam populações tradicionais ${ }^{4}$. Descreve, de forma geral, o ecossistema de manguezal e as especificidades das populações que nele vivem, em especial aquela encontrada na área lócus do estudo.

O Brasil tem o segundo maior complexo de manguezais do mundo, com aproximadamente $13.400 \mathrm{~km}^{2}$ (SOUZA-FILHO, 2005). Mesmo sendo um ecossistema singular, o mangue pode ser encontrado em várias partes das regiões tropicais do planeta (ALVES, 2001). Enquanto ecossistema, ele resulta do encontro das águas doce e salgada, formando um ambiente de água salobra de salinidade variável e exclusivamente encontrada em regiões costeiras (TOMLINSO, 1986; ALVES, 2001).

Os impactos da ação humana sobre os mangues podem ser percebidos em esfera planetária. Um controle sobre esses berçários de vida demanda esforços

\footnotetext{
4 A definição de populações, povos e comunidades tradicionais é variada. Desde instrumentos jurídicos, administrativos, passando pela discussão acadêmica, este conceito assume diversos contornos. Utilizam-se neste trabalho os conceitos elaborados por Almeida (2008), Cunha e Almeida (2001) e Diegues (1993; 2001) que enfatizam, cada um a sua maneira, duas características essenciais dessa categoria analítica, a saber: a dimensão de uma identidade jurídica e política do conceito, assim como a dimensão socioambiental atrelada ao mesmo. O conceito jurídico adotado repousa na definição encontrada no decreto 6.040/07 que assim se manifesta em seu artigo terceiro, inciso primeiro: "Povos e Comunidades Tradicionais: grupos culturalmente diferenciados e que se reconhecem como tais, que possuem formas próprias de organização social, que ocupam e usam territórios e recursos naturais como condição para sua reprodução cultural, social, religiosa, ancestral e econômica, utilizando conhecimentos, inovações e práticas gerados e transmitidos pela tradição". Para um panorama completo da construção do conceito consultar Ravena-Cañete (2012).
} 
tanto locais, como em esfera da gestão regional, nacional e mesmo por meio de intervenções efetivadas por instituições globais.

Marcado pela transição entre o ambiente costeiro e marinho, o mangue vive sob os efeitos das marés e apresenta fauna e flora específicas, além de um relevo particular composto de rios, desembocaduras, lagos e reentrâncias costeiras somadas a todas as áreas que permitem o encontro entre águas doces e marinhas ${ }^{5}$.

A cobertura vegetal, ao contrário do que acontece nas praias arenosas e nas dunas, instala-se em substratos de várzea de formação recente, de pequena declividade, sob a ação diária das marés de água salgada ou, pelo menos, salobra (MENEZES; BEGER; MEHLIG, 2008). A riqueza biológica dos ecossistemas costeiros faz com que essas áreas sejam grandes "berçários" naturais, tanto para as espécies características desses ambientes, como para peixes e outros animais que migram para as áreas costeiras durante, pelo menos, uma fase do ciclo de sua vida (SCHAEFFER-NOVELLI, 1989).

No Brasil, os mangues são protegidos por legislação federal, devido à importância que representam para o ambiente marinho (PEREIRA FILHO; ALVEZ, 1999 apud ALVES, 2001). São fundamentais para a procriação e o crescimento dos filhotes de vários animais, como rota migratória de aves, pescados e alimentação de peixes. Além disso, colaboram para o enriquecimento das águas marinhas com sais, nutrientes e matéria orgânica.

A área norte do Brasil, mais especificamente o estado do Amapá, integra o complexo de manguezais dessa região do território nacional, despontando como uma das maiores áreas contínuas de mangue do mundo. A foz do rio Cassiporé, localizada no interior do PNCO (município de Oiapoque e Calçoene), se destaca por ser um local de desova e criação de juvenis de diversas espécies de pescados. Considerando as preocupações ambientais, essa área foi escolhida para a instituição do PNCO.

Referendando esse cenário de riqueza e diversidade ambiental, o PNCO foi criado a partir de recomendações do projeto Radar na Amazônia (RADAM), devido ao estudo "Uma análise de prioridades em conservação da natureza na Amazônia”, produzido por Wetterberg et al. (1976). Após as recomendações da instituição do PNCO o mesmo foi incluído no Plano do Sistema de Unidades de Conservação do Brasil (IBDF; FBCN, 1979 apud ICMBio, 2010), com as seguintes justificativas:

A proposição para criação dessa unidade de conservação é justificada a partir de itens importantes segundo critérios de avaliação de significância utilizados dentro do Plano do Sistema de Unidades de Conservação,

\footnotetext{
Vasta literatura sobre o mangue amazônico pode ser encontrada. No entanto, algumas obras chamam a atenção por apresentarem um caráter interdisciplinar. Nesse sentido, consultar: Furtado, Silveira e Santana (2012).
} 
que são os seguintes: representatividade de biomas anfíbios (campos de várzea e mangues) de grande importância como amostra única do Brasil; representação da planície flúvio-marinha Macapá-Oiapoque; representação de habitats de várias espécies ameaçadas de extinção: oito mamíferos, sete de aves e possivelmente duas de répteis, representação numa mesma área de mangues, praias lodosas, praias arenosas, dunas, campos de várzea, floresta, cerrados, lagos de água doce, salobra e salgada, rios, estuários e etc.; baixa densidade demográfica e baixo nível tecnológico. Em decorrência de todos os fatores apresentados, a área possui um elevado potencial educativo, com oportunidade interpretativa ímpar, um potencial científico e de monitoramento muito grande, prestando-se a estudos científicos e técnicos, e representa a natureza em todo o seu teor selvagem, e inóspita devido ao difícil aproveitamento para atividades econômicas tradicionais (ICMBio, 2010, p. 66).

Utilizando uma lógica preservacionista que marcou as décadas de 1970 e 1980, a gestão federal buscou consolidar diversas áreas protegidas em modelos de parques. Assim, a preocupação ambiental permanece como tema no contexto nacional e passa a compor a norma jurídica como consta no artigo 225 do capítulo VI da Constituição Federal de 1988 que prevê que: "Todos têm direito ao meio ambiente ecologicamente equilibrado, bem de uso comum do povo e essencial à sadia qualidade de vida, impondo-se ao poder público e à coletividade o dever de defendê-lo e preservá-lo para as presentes e as futuras gerações". Considerando esse pressuposto, a criação do parque resguarda apenas a perspectiva ecológica e ambiental de uma área, no entanto, exclui por completo qualquer tipo de população tradicional que possivelmente poderia residir no interior do Parque.

Dessa forma, a população que vivia na área que posteriormente se constituiria o PNCO desfrutava da rica biodiversidade e disponibilidade de recursos naturais como caça, pesca, extrativismo e criação de animais ${ }^{6}$. Essa população se concentrava quase exclusivamente na Vila de Taperebá. A população da Vila era uma comunidade pesqueira que desenvolvia suas atividades em parte do rio Cassiporé e em sua foz. Essa se mostra como uma área de extrema riqueza ambiental e recursos naturais como relatado pelos moradores.

A Vila de Taperebá está localizada na foz do rio Cassiporé, e seu ambiente de mangue dispõe de uma vasta variedade e quantidade de pescados. Como é uma área de desova e berçário de juvenis, diversas espécies, principalmente a gurijuba e a pescada amarela, que são pescados altamente valorizados no mercado, se concentram em cardumes nas águas costeiras e foz do rio Cassiporé.

\footnotetext{
A criação de animais não deve ser entendida aqui como uma prática que caracteriza um setor econômico, mas, apenas, como uma atividade de subsistência. A criação de galinhas e porcos estava presente no discurso dos entrevistados, sendo que o gado também apareceu de forma recorrente.
} 
É importante salientar a diminuição no tamanho dos pescados, nos últimos 30 anos. Com a grande pressão do mercado interno e externo, os pescados estão sendo capturados cada vez mais jovens e de forma desordenada. Dessa forma, os pescados passam a ser mais escassos e menores, pois, não dispõem de tempo suficiente para reprodução e crescimento. A fala de um antigo morador da Vila de Taperebá é elucidativa.

Antigamente era só peixe graúdo difícil você pegar uma gurijuba pequena que nem hoje em dia, antes era daquelas grandes [...] a gente pescava de arpão, na praia, eu lembro que em lua cheia elas iam pras praias e lá a gente ia entrando na beira e via elas, daí pegava com o arpão só graúda. Hoje em dia, hummm [...] difícil pegar uma gurijuba com barco, imagina na praia (Pesquisa de campo, J. 45, 2013).

Atualmente o ciclo de reprodução do pescado sofre com a pesca sem controle. O presidente da Colônia dos Pescadores de Oiapoque Z-3, juntamente com alguns colonizados, relata o exemplo da gurijuba, dizendo que era difícil a captura de uma gurijuba de tamanho pequeno a médio estando ovada ${ }^{7}$, apenas as gurijubas maiores eram pescadas nessa condição. No entanto, atualmente essa espécie está sendo capturada ovada e ele assevera que elas evoluíram para tentar sobreviver, mudando o seu ciclo biológico para que a espécie se perpetue. A seguir, a partir de uma fala do presidente da Colônia de Pescadores Z-03, é possível elucidar tal argumentação.

[...] se nós observarmos hoje em dia, o peixe está ovado pequenininho a gurijuba, pescada branca, pescada amarela, bandeirado [...] e antigamente não era assim, pra pescar uma gurijuba ovada, ixi, só aquelas graúdas mesmo. Então isso que tem que ver, mudou tudo, é que nem hoje em dia você ver menina de doze anos parindo e antigamente não se via. Então o peixe tá mudando também. Isso que é que a gente vê (Pesquisa de campo, J. 45, 2013).

Ademais da quantidade e tamanho dos pescados, uma forte recordação e que se faz muito presente nas argumentações dos entrevistados é a arte de pesca. Antes, os apetrechos, as técnicas e as $\operatorname{artes}^{8}$ de pesca eram em sua maioria de pequena escala e seletivos quanto a tamanho e quantidade dos pescados. Os apetrechos mais utilizados eram o arpão e o espinhel ${ }^{9}$, que para eles, em sua atual percepção de escassez de recursos, eram os menos agressivos para as espécies capturadas. O presidente da Colônia de Pescadores Z-03 evidencia, ainda, que este tipo de técnica perdurou até meados da década de 1980 em toda costa amapaense. Sua fala anuncia tal percepção.

\footnotetext{
Termo utilizado pelos pescadores para evidenciar que o pescado está com ovas, ou seja, em seu período de reprodução.

8 Para saber mais sobre técnicas e arte de pesca, ver Mourão et al. (2009).

9 Uma linha que dispõe de vários anzóis. Para saber mais sobre essa arte de pesca, ver Mourão et al. (2009).
} 
Antes a gente usava mais o espinhel e o arpão, esses eram os principais apetrechos de pesca da costa do Amapá, dava pra conferir quem não era, tinha a zangaria que era uma pesca predatória, mas a maioria dos pescadores era de espinhel, até os vigienses. Há uns 30 anos atrás que chegou a rede, né e uns 20 anos que começou com força (Pesquisa de campo, J. 45, 2013).

Os relatos apresentados descrevem a abundância dos recursos naturais na Vila de Taperebá no século passado e o fácil acesso e uso dos mesmos. A população que viveu na Vila dispôs de recursos naturais em abundância, no entanto, a partir da criação do PNCO essa disponibilidade foi se transformando. A próxima seção mostrará como houve um impacto na vida e cotidiano da população a partir da criação do parque.

\section{INSTITUIÇÃO DO PNCO: CONFLITOS SOCIAIS E AMBIENTAIS}

Esta seção aborda a instituição do PNCO e os vários cenários de conflito que se estabeleceram a partir das ações do governo federal sobre os moradores que viviam na Vila de Taperebá, às margens do rio Cassiporé.

O PNCO hoje é composto por um território com aproximadamente 200 $\mathrm{km}$ contínuos de costa e mangue. Nessa área houve uma intensa disputa ao longo dos séculos XVII, XVIII e XIX por diversos colonizadores: portugueses, franceses, ingleses e holandeses. Foi uma região que abrigou variadas denominações, inicialmente como "Cabo Cecil", posteriormente "Cabo de la Corda", por fim, em meados do século XVII, Johannes de Laet, um navegador holandês, homenageou a família Orange dotando o nome real à localidade. A palavra orange significa laranja em holandês e a mesma é a cor nacional da Holanda (ICMBio, 2010).

Como mencionado, o Parque Nacional do Cabo Orange foi instituído a partir de um estudo realizado em meados da década de 1970, quando, em um cenário nacional mais amplo, uma sobrexplotação dos recursos naturais começou a se delinear e com o consequente esgotamento dos mesmos ${ }^{10}$. Dessa forma, um estudo ecológico ambiental foi realizado nessa área de mangue do estado do Amapá, mais especificamente na foz do rio Cassiporé, próximo à Vila do Taperebá. Nessa vila, segundo relatos do presidente da Colônia de Pescadores Z-03 do Oiapoque ${ }^{11}$, morador da vila por vinte anos, havia cerca de cem famílias

10 Estas informações foram retiradas do site do Instituto de Chico Mendes de Proteção a Biodiversidade, mais precisamente no Plano de Manejo Parque Nacional do Cabo Orange. Brasília, 2010.

11 Os dados sobre a história da Vila de Taperebá e os processos de desapropriação correspondem aos relatos de diversos pescadores do Oiapoque que na vila viveram. Dentre estes, destacam-se os relatos do senhor Julio Garcia, presidente da Colônia de Pescadores Z-03, que além de ter vivido o processo de expropriação, evidencia uma visão refinada e crítica sobre esse processo. 
e aproximadamente mais de quatrocentas pessoas secularmente instaladas na localidade. Hoje, apenas quatro famílias ainda resistem na Vila de Taperebá.

As principais populações que se localizavam no território que iria ser instituído como PNCO estavam nas vilas do Taberebá e Cunani. A primeira, localizada às margens do rio Cassiporé, e a segunda, às margens do rio Cunani, como apresenta a Figura 1.

Figura 1 - Localidade das antigas comunidades de Taperebá e Cunani no interior do PNCO

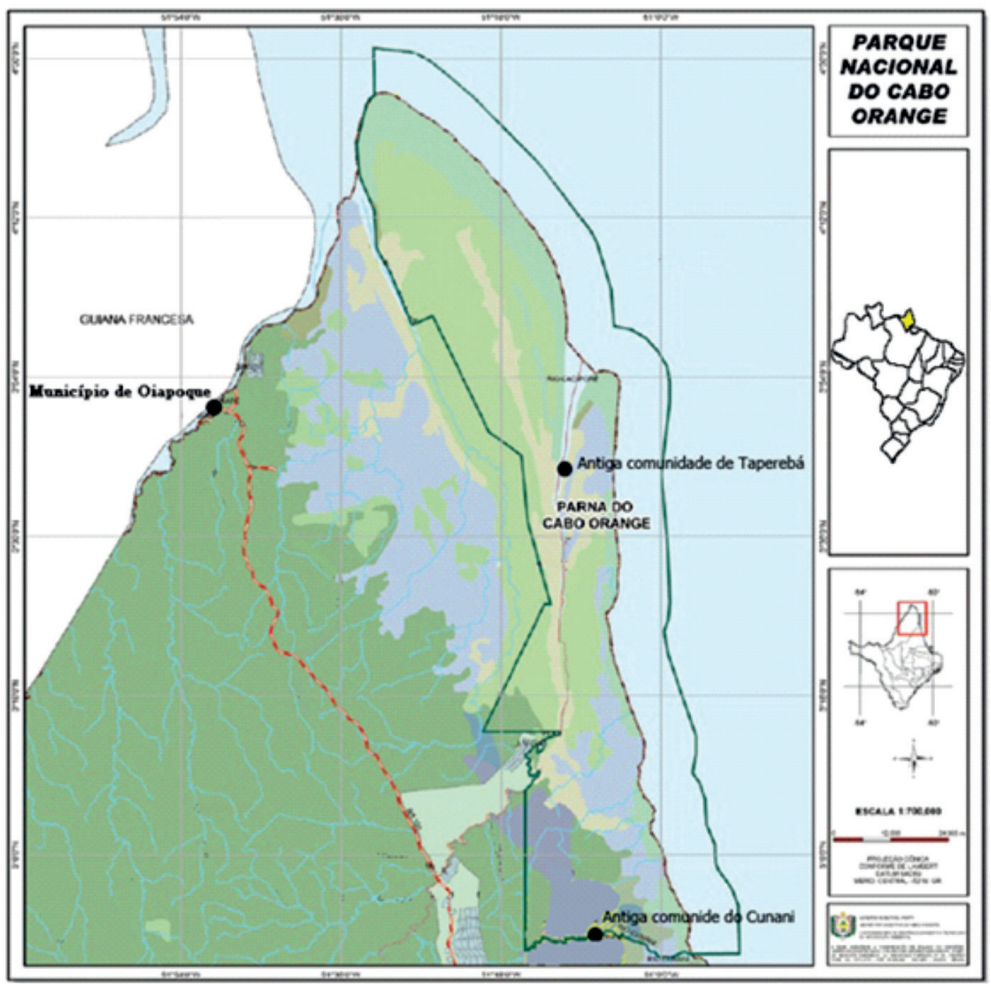

Fonte: adaptado do ICMBio (2010)

A instituição do PNCO foi concretizada em 15 de agosto de 1980 pelo Decreto $\mathrm{n}^{\circ} 84.913$, e, a partir de sua criação, conflitos socioambientais tomaram grandes proporções nesse cenário local. Mais uma vez, segundo o depoimento de antigos moradores, não houve desapropriação efetiva, mas sim um processo onde o governo federal dificultava a permanência daquela população na vila. A estratégia utilizada pelos governos federal e estadual, para a expulsão dos moradores, foi a de interromper o oferecimento nos serviços públicos básicos de saúde e educação, dentre outros. 
Segundo o relato de pescadores remanescentes da Vila de Taperebá, no ano de 1980 o Instituto Brasileiro de Desenvolvimento Ambiental (IBDF) foi à localidade apenas colocar as placas de instituição do Parque. No entanto, o mesmo não informou a população, de forma adequada, sobre a criação dessa área de proteção integral. O relato a seguir exemplifica o comportamento estabelecido pelo IBDF: "Antigamente não tinha fiscalização, ai fizeram o Parque e largaram lá, depois de uns anos pra cá que eles vieram com essa fiscalização e ficou meio apertado, né e a gente teve que sair" (Pesquisa de campo, J. 38, 2013). Dentre os informantes, a fala do atual vice-presidente da Colônia de Pescadores Z-03 do Oiapoque ressalta o detalhamento da chegada e ação do IBDF junto à comunidade Vila de Taperebá.

Eles chegaram dizendo que era só uma demarcação federal, que nada seria mudado era só uma coisa de mapeamento mesmo e as pessoas continuariam vivendo, pescando, criando [...] aí eu vim de Cassiporé ${ }^{12}$ pra cá em 1988 e já estava bem avançado né, já tava começando a ficar difícil viver lá. Aí cada ano foi apertando mais. Desde uns três anos depois da criação do Parque eles frequentavam a Vila pra dizer que não ía poder roçar, pescar, caçar, só com permissão do IBAMA e essa permissão foi que depois originou o nosso atual acordo, poder pescar com um limite, pode pescar durante dez dias, depois entra outra equipe, entendeu? (Pesquisa de campo, M. 45, 2013).

As fiscalizações referidas pelo entrevistado são as visitas realizadas pelo IBAMA $^{13}$ para averiguar se havia alguma irregularidade ambiental no território do PNCO. Dessa forma, como evidenciado na fala acima, as fiscalizações foram iniciadas apenas, aproximadamente, três anos após a primeira visita do IBAMA à Vila, na qual se anunciava o estabelecimento da criação do parque. Os agentes do IBAMA visitaram a comunidade e informaram aos moradores que todos os benefícios disponibilizados à comunidade como, gerador de energia, abastecimento de diesel, pagamento de funcionários públicos como professores, médicos, enfermeiras, liberdade do acesso e uso dos recursos naturais seriam eliminados e proibidos.

Os remanescentes da comunidade alegam que com esse ato do Governo Federal a estadia deles na Vila ficou abalada, ameaçada e cada vez mais difícil. Tal argumentação expressa um contexto marcado por um processo de limitação

12 Os moradores da Vila de Taperebá referenciam o antigo lugar de moradia como Cassiporé. Essa autodefinição se explica dado que a Vila de Taperebá, como mencionado, se localiza às margens do rio Cassiporé, como elucidado na Figura 2.

13 O Instituto Brasileiro do Meio Ambiente e dos Recursos Naturais Renováveis (IBAMA) foi instituído em 22 de fevereiro de 1989, pela Lei no 7.735 (http://www.ibama.gov.br/acesso-ainformacao/historico). Dessa forma, quando se iniciou o processo de fiscalização do PNCO, na década de 90 do século passado, a instituição responsável pelas missões era o IBAMA. 
e exclusão, já que esses moradores foram impedidos de pescar, caçar, cultivar e criar animais nos territórios da comunidade.

Ademais de dificultar o modo de vida ${ }^{14}$, havia uma pressão do IBAMA sobre os moradores. Este utilizava a argumentação de que era proibido viver dentro do Parque, como é possível ver na seguinte declaração de um entrevistado: "a gente veio embora porque eles começaram a proibir a pesca, o IBAMA falava que era pra vir embora de lá. Aí não tinha mais escola pros meus filhos. Aí desgostou né [...] de lá. Ficou tudo difícil lá e o IBAMA falou que era pra vir embora" (Pesquisa de campo, M. 33, 2013,).

O IBAMA, para cessar a pesca na foz e no rio Cassiporé, jogou uma enorme barra de ferro no leito do rio para que os apetrechos de pesca não fossem lançados à água. Para ampliar a percepção do cenário passado, a fala de um ex-morador exemplifica a realidade experimentada pelo mesmo a partir da instituição do parque.

muito moradores de lá não saíram, porque não tinham expectativa de vida aqui no Oiapoque. A gente não sabia fazer outro trabalho. Mas o que acontece, hoje eu acredito que não vai ser diferente pra nós aqui, o Parque lá já foi fechado há muito tempo, lá mora só alguns [...] Umas cinco ou seis famílias. Então eles chegaram com essa ideia, não permitiam que as pessoas pescassem, era proibido, inclusive jogaram um ferro no rio que era pra gente nem soltar mais a malhadeira, acho que ainda existe isso ainda lá. Porque se jogasse a rede, prendia e perdia todo o material. Então era Parque, era lei o que vale é o que estava no papel a palavra não vale nada. Então hoje eu acho que não é diferente, porque eu já ouvi um projeto que a Petrobras que vai fazer umas plataformas aí fora, não sei quantas milhas pra fora, não sei se vai prejudicar nós, então os moradores do Taperebá se sujeitaram a vir pro Oiapoque, porque não tinha como permanecer lá! Como vai pescar pra manter a família, era área de Parque como a gente ia fazer, né? Eu me recordo de algumas vezes, eles iam lá e fiscalizavam e vendo se as pessoas não estavam pescando (Pesquisa de campo, M. 33, 2013).

Após a criação do parque não houve nenhum tipo de compensação ou indenização para aqueles moradores. Como visto nos relatos, essa população sofreu forte pressão e intimidação dos órgãos responsáveis para que deixasse o local. Dessa forma, ademais de não haver uma correta indenização no processo de instituição da área protegida, o governo isentou-se de seus deveres e mesmo

14 Modo de vida é uma categoria que aparece de forma diluída na literatura das Ciências Sociais. No entanto, neste trabalho, entende-se modo de vida como uma forma de viver marcada por uma lógica orientada por uma relação específica com os recursos naturais e como materialmente e simbolicamente uma população se relaciona com a sociedade do entorno e historicamente se constrói. Para discutir sobre essa temática, ver Abramovay (2003) e Veiga (2002). 
que o tivesse feito, seria possível mensurar o preço das memórias e do modo de vida daquela população para eles mesmos? Ou seja, esse raciocínio esbarra na questão de “comensurar o incomensurável ${ }^{15 "}$ (CAVALCANTI, 2004, p. 152).

Os interesses políticos e econômicos ultrapassam os valores do meio ambiente (CAVALCANTI, 2004), e dessa forma, são instituídos meios e métodos que fazem com que a população tradicional seja espoliada e marginalizada (ALMEIDA, 2008). Os moradores da Vila de Taperebá foram impedidos de pescar na localidade e encontraram dificuldades até mesmo em pescar para o próprio consumo, que à época era permitido. A ilegalidade se caracterizava pelo comércio dos recursos naturais do território do parque.

Ademais das proibições ao acesso e ao uso dos recursos naturais, houve mais dificuldades impostas pelo governo aos moradores da Vila de Taperebá. Os mínimos serviços públicos que eram oferecidos foram cessados causando um desgosto na população. Tal pressão governamental resultou na migração desses moradores. O relato em seguida elucida esse contexto de desgosto.

O governo dava muita ajuda, tinha escola, hospital, remédio, diesel com gerador, e aí a gente ficou esquecido. Daí foi desgostando de lá e a gente foi saindo. Eles começaram a proibir tudo. A gente tinha uma boa comunidade lá, tinha escola, tinha gerador, o governo mandava combustível, tinha gente que comprava os nossos peixes. Daí o IBAMA foi proibindo tudo, não podia mais pescar, caçar, plantar, só podia pescar pra gente mesmo, não podia vender. Daí eles fecharam a escola ficou sem escola, foi tudo ficando difícil né (Pesquisa de campo, J. 39, 2013).

A partir desses dados históricos, apresenta-se um quadro que permite sistematizar, de forma mais sucinta, o histórico de conflitos vivenciados pelos moradores da Vila de Taperebá.

15 Este termo merece uma abordagem maior, dessa forma, coloca-se a citação do autor para elucidar melhor o mesmo "Os custos associados a esses processos destruidores não são normalmente estimados: eles não aparecem nas estimativas das contas nacionais, exceto como fatores positivos e até como nova adição aos valores do PIB quando se consideram as despesas para consertar erros ecológicos cometidos, a exemplo de uma vazão tóxica como a de Cataguases em março de 2003 (cloro e soda cáustica, de uma fábrica de papel, lançados no rio Pomba, afluente do Paraíba do Sul). Estimar o valor monetário de recursos naturais esgotados como meio de aferir se o desenvolvimento tem sido sustentável representa uma iniciativa para, pelo menos, se ter uma ideia econômica das externalidades negativas geradas. Essa é a esfera de domínio da economia ambiental, com a qual se coloca o sistema ecológico na perspectiva da abordagem econômica. A valoração econômica ambiental interessa cada vez mais a gestores, estudantes, pesquisadores e profissionais. Trata-se de área de fronteira da ciência econômica, nem sempre aceita pacificamente, uma vez que se levanta contra ela a pertinente questão de comensurar o incomensurável" (CAVALCANTI, 2004, p. 152). 
Quadro 1 - Histórico de conflito do objeto desta pesquisa

\begin{tabular}{|c|c|c|}
\hline Período & Agentes envolvidos no conflito & Motivos do conflito \\
\hline $1930-1980$ & $\begin{array}{l}\text { Não há relatos de conflitos } \\
\text { complexos }\end{array}$ & $\begin{array}{l}\text { Não há relatos de conflitos } \\
\text { complexos }\end{array}$ \\
\hline $1980-1985$ & $\begin{array}{llll}\text { Conflito entre o IBAMA } & \text { e } \\
\text { moradores da Vila de Taperebá } & \end{array}$ & Acesso e uso dos recursos naturais \\
\hline $1990-2000$ & $\begin{array}{l}\text { Conflito entre o IBAMA e } \\
\text { moradores da Vila de Taperebá }\end{array}$ & $\begin{array}{l}\text { Acesso e uso dos recursos naturais } \\
\text { na área da Vila de Taperebá que } \\
\text { passou a compor o território do } \\
\text { PNCO e pela estadia da população } \\
\text { na comunidade. }\end{array}$ \\
\hline $2000-2012$ & $\begin{array}{l}\text { Conflito entre o IBAMA e } \\
\text { moradores da Vila de Taperebá; } \\
\text { Conflito entre frotas pesqueiras } \\
\text { maiores e de outras localidades } \\
\text { com os pescadores do Oiapoque } \\
\text { e com embarcações de pequeno } \\
\text { porte }\end{array}$ & $\begin{array}{l}\text { Conflitos por área de pesca e } \\
\text { fiscalização no PNCO, pois os } \\
\text { barcos de outras localidades não } \\
\text { respeitam as leis de proteção } \\
\text { ambiental do PNCO }\end{array}$ \\
\hline $2012-2014$ & $\begin{array}{l}\text { Conflito entre o IBAMA e } \\
\text { moradores da Vila de Taperebá; } \\
\text { Conflito entre frotas pesqueiras } \\
\text { maiores e de outras localidades com } \\
\text { os pescadores do Oiapoque e com } \\
\text { embarcações de pequeno porte }\end{array}$ & $\begin{array}{l}\text { Conflitos por área de pesca, } \\
\text { fiscalização no PNCO e conflito } \\
\text { entre pescadores que fazem parte } \\
\text { do Termo de Compromisso com } \\
\text { os que não fazem parte do Termo }\end{array}$ \\
\hline
\end{tabular}

Fonte:

Como mencionado, as áreas protegidas eram pensadas a partir de uma lógica preservacionista em um modelo de área ambiental onde o homem não estava incluído, sendo a mesma utilizada apenas para estudo, lazer e admiração (DIEGUES, 2001). A partir de uma perspectiva histórica para a instituição das unidades de conservação, identificam-se diversas etapas de análises para uma melhor adaptação da lei diante da realidade local. A lei no 9.985/2000, que instituiu o Sistema de Unidade de Conservação da Natureza (SNUC), passou por diversas adaptações e processos de refinamento que merecem detalhamento.

Antes da lei No 9.985/2000 mencionada acima, os processos de criação e instituição de áreas protegidas aconteciam com regras pouco definidas, muitas vezes confusas e conflitantes, de toda forma, marcadas por uma baixa ou nenhuma participação e escuta das comunidades afetadas pelo processo. No caso do PNCO, esse contexto não foi diferente. Este que foi instituído em 1980, sendo o processo de instituição do mesmo realizado apenas no papel $^{16}$, não contou com

16 Esta situação em que unidades de conservação que não saíram do "papel", é detalhada por Antonaz (2009). 
audiências públicas, tampouco acordos com as populações residentes dentro do território do parque. O governo quando criou essa área protegida não avaliou os impactos para a criação da mesma no que se refere aos modos de vida dessas populações, pois essas, centenárias, eram as responsáveis pela preservação e manutenção desse território (DIEGUES, 2001).

Segundo Diegues (2001), as populações que são desapropriadas de uma localidade objetivando a instituição de uma unidade de conservação, de âmbito preservacionista, são marcadas por um baixo conhecimento, ou mesmo ausência do mesmo, no que se refere aos seus direitos socioambientais. Na maioria dos casos, além de serem marginalizadas, apresentam pouca ou nenhuma expressão política, quando considerada a área de decisões colocada pelo Estado frente às questões ambientais. Dessa forma, essas populações são facilmente expulsas, sem que haja um processo legal e justo, assim como quase nunca conseguem uma indenização justa pela desapropriação.

Ademais de não avaliar os impactos no modo de vida dessas populações, o governo federal brasileiro tampouco avaliou os impactos ambientais que a criação do parque provocaria por excluir o homem do meio ambiente, como se este não estivesse integrado na vida natural. Nesse sentido, em uma perspectiva oposta àquela que originou a criação do PNCO, vale evocar Diegues (2001), que entende que o homem não está excluído do meio ambiente, mas faz parte dele. Para o autor, o ser humano, assim como toda a fauna e flora no planeta, dispõe de uma função na natureza e excluí-lo dela é um equívoco.

Outro aspecto não avaliado pelo governo brasileiro foi o sentimento de pertença ${ }^{17}$ que a população, moradora da Vila de Taperebá, no interior do parque, apresentava pelo território que habitava. Essa população apresentava conectividade com a localidade e nesse sentido, almejava ocupar outra localidade com a mesma lógica utilizada na área da qual foi desapropriada. Sendo assim, muitas vezes a comunidade pode desintegrar-se e acabar sendo extinta, pois não consegue adaptar-se em outros ambientes, já que tenta reestabelecer o cenário de origem no qual vivia.

Dessa forma, os cenários que envolvem as UC e as populações tradicionais espoliadas são cenários de conflitos que perpassam questões que envolvem desde a ecologia, a política, o direito, a sociedade, entre outras áreas. O caso específico

17 Para este conceito é necessário uma abordagem mais significativa, segundo Jeronimo e Gonçalves (2008, p. ...): "sentimento de pertença deve ser tomado como que um habitante tem sobre um espaço em particular entre a posse do espaço e a autoimagem e identidade social daquele que ali habita". Dessa forma, o sentimento de pertença pode ser entendido como uma espécie de mescla de territorialidade e a apropriação que uma pessoa estabelece em certo ambiente. 
do PNCO apresentou dois grandes conflitos. Primeiramente o conflito para o acesso e uso dos recursos naturais e posteriormente a estadia em uma área protegida. Nesse sentido, a exclusão e a falta de assistência a essas populações tradicionais se desdobrou em outro conflito que se evidenciou na disputa do acesso e uso dos recursos naturais com outras populações pesqueiras. O próximo subitem apresentará o cenário posterior à criação do PNCO, assim como os novos desdobramentos e conflitos que essa população remanescente vivencia.

\section{À GUISA DE CONCLUSÃO: CONFLITOS POR TERRITÓRIOS DE PESCA NO OIAPOQUE E TERMO DE COMPROMISSO}

Este item tem por objetivo apresentar o atual cenário de conflito que envolve os pescadores artesanais do município de Oiapoque, assim como evidenciar o termo de compromisso como uma estratégia de manejo, fechando, portanto, o caso descrito. Nesse sentido, relata-se a invasão dos barcos paraenses em águas amapaenses, destacando como essa migração de pesca tem tomado força nos últimos vinte anos em decorrência do esgotamento dos recursos pesqueiros em águas paraenses. Desde o ano de 2008 o município vive o ápice dessa migração. Ademais desse cenário, esta seção trabalha o período a partir de 2012, no qual a organização dos pescadores do município do Oiapoque instituiu, por meio da Colônia de Pescadores Z-03, IBAMA e MPF, um termo de compromisso como ferramenta de manejo e diminuição de conflito entre os diferentes agentes que acessam e usam o território pesqueiro no interior do PNCO.

Devido à sobre-explotação dos estoques de pescado em várias partes do país, os recursos pesqueiros passaram a sofrer forte diminuição em águas oceânicas nacionais. Nesse sentido, vale salientar que o Pará dispõe atualmente de um baixo recurso pesqueiro ${ }^{18}$, mesmo sendo um dos principais estados brasileiros de desembarque e exportação de pescado. Segundo relatos dos pescadores entrevistados somado às literaturas que abordam esta temática (MOURÃO et al., 2009), a frota pesqueira de médio e grande porte do Pará tem preferência de captura pesqueira pela costa amapaense. O estado do Amapá dispõe de uma costa ainda muito piscosa e este motivo figura como um dos grandes fatores para a migração dos pescadores paraenses para essa região.

Devido ao intenso fluxo de grandes barcos pesqueiros de outros estados na região amapaense, especialmente os do Pará, a costa do Amapá é considerada

18 Essa informação resulta de observação direta em campo, somada aos relatos dos pescadores, estes obtidos no decorrer de pesquisa de campo especialmente junto aos presidentes das principais colônias de pecadores do salgado paraense. 
a região com maior tráfego de barcos cadastrados e fiscalizados pelo Programa Nacional de Rastreamento de Embarcações Pesqueiras por Satélite (PREPS) (ICMBio, 2010). A Figura 2 apresenta a migração das frotas pesqueiras de outros estados que vêm desde o Ceará, passando pelo Maranhão, Pará e, por fim, chegando ao Amapá, elucidando o processo que origina o contexto de pressão sobre os recursos pesqueiros no extremo norte do Brasil.

Figura 2 - Área de migração das grandes embarcações que vão pescar no extremo norte do Brasil, em águas amapaenses

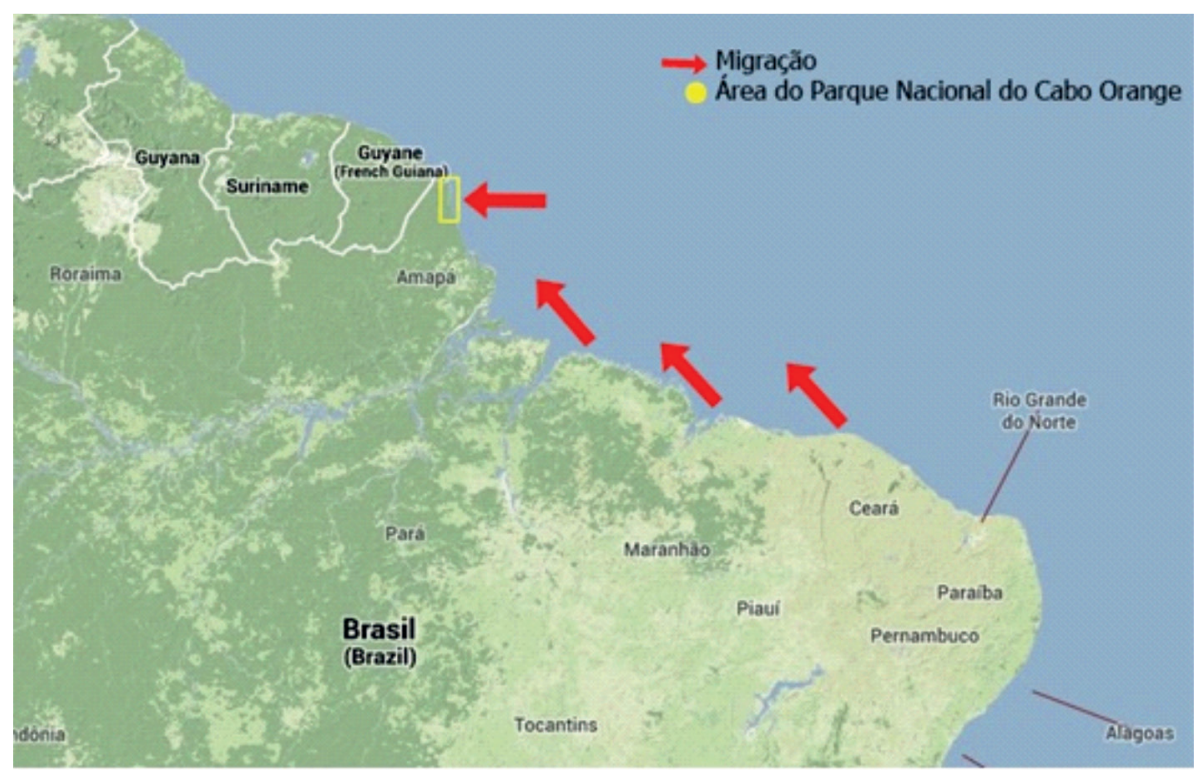

Fonte: Adaptado do Google Maps (2013)

A forte invasão de barcos instala-se principalmente na costa amapaense. Desse modo, devido à localização geográfica do Oiapoque, com áreas de pesca limitadas, a sobrevivência e a perpetuação da pesca de pequeno porte e tradicional fica extremamente limitada. Na Figura 3 é possível identificar a limitação de áreas de pesca, disponibilizada para os pescadores do Oiapoque. Ao lado esquerdo/ norte do município de Oiapoque as águas são francesas e proibidas para a pesca, no lado direto do rio Oiapoque fica a boca do rio Uaçá onde se localiza a área indígena Uaçá, também interditada à pesca, as 6 milhas de costa ao sul são águas protegidas do PNCO e, por fim, das 6 milhas em diante de águas protegidas do PNCO há uma grande competitividade e conflito por território de pesca, ademais da dificuldade de navegação por serem barcos pequenos e de pouca estabilidade em mar aberto. A Figura 3 permite visualizar esse contexto de limitações. 
Figura 3 - Elucidação do pequeno território que os pescadores artesanais do Oiapoque dispõem para pescar

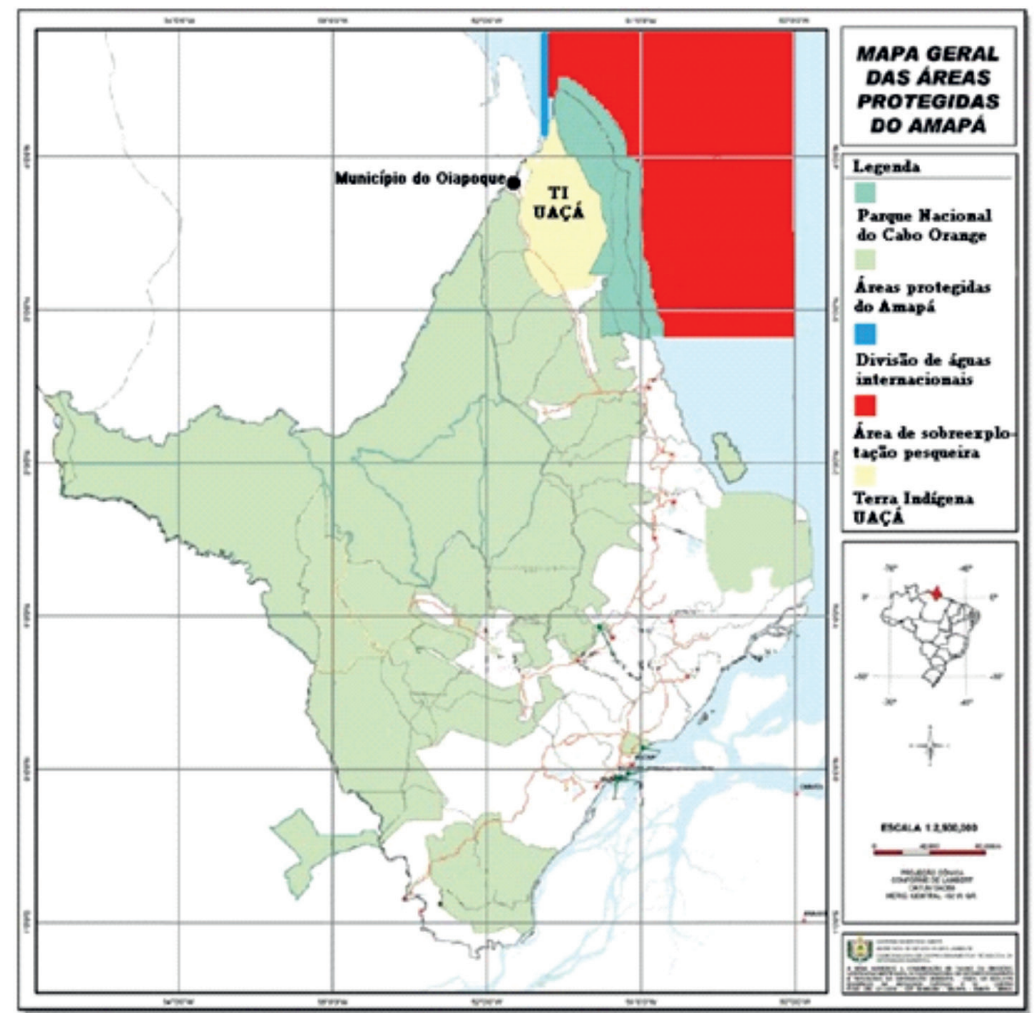

Fonte: Adaptado de ICMBio (2010)

O parque tem limitação de seis milhas de espelho d'água, e a pesca nesse território é proibida, pois trata-se de uma área de UC (preservacionista). Contudo, a partir do termo de compromisso instaurado no ano de 2012, embarcações de pequeno porte cadastradas na Colônia de Pescadores Z-03 de Oiapoque e que façam parte de tal termo podem ingressar em parte do território do PNCO para pescar.

O termo de compromisso em questão foi criado a partir da percepção do presidente da Colônia de Pescadores Z-03 de Oiapoque no que se refere à necessidade de uma compensação aos moradores após a instituição do PNCO, dado que os mesmos não contaram sequer com uma indenização quando foram retirados da Vila de Taperebá. Dessa forma, em 2012 foi criado o termo de compromisso, com o propósito de permitir a pesca pelo período de dois anos, podendo o mesmo ser estendido por mais dois anos consecutivos. Durantes esse período, a população beneficiada, juntamente com os órgãos responsáveis pelo PNCO, deverão discutir uma solução institucional para o cenário de conflito. 
Abaixo, a partir de uma figura adaptada, é possível visualizar a área do parque que faz parte do termo de compromisso.

Figura 4 - Área do Parque Nacional do Cabo Orange que faz parte do termo de compromisso $\mathrm{n}^{\mathrm{O}} 2012$

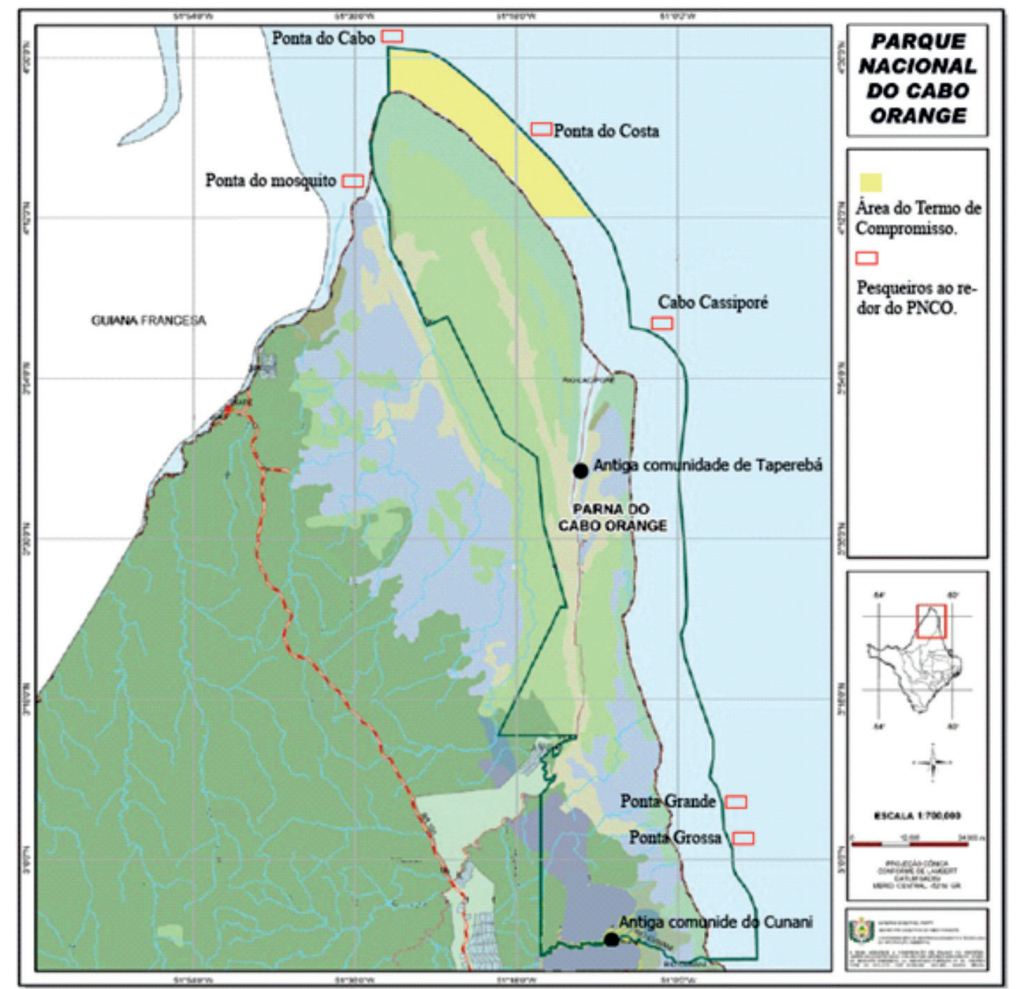

Fonte: adaptado de ICMBio (2010)

O termo atende a demanda de populações tradicionais costeiras do Oiapoque que são, em sua maioria, remanescentes da Vila de Taperebá, possibilitando, em um sistema de rodízio, o acesso e o uso dos recursos pesqueiros em parte do PNCO. A Colônia de Pescadores Z-03 do Oiapoque tem em seus registros 175 barcos cadastrados, no entanto, apenas 70 desses barcos têm permissão para pescar no parque como especificado no termo de compromisso acordado em 2012, onde o mesmo estabelece como pescador artesanal: "II - DO OBJETO, Cláusula Primeira $\int 1^{\circ}$ - Para os fins deste termo de compromisso, entende-se por pesca de pequeno porte aquela não superior a duas toneladas semanais de peixe por embarcação".

O termo de compromisso funciona a partir de um processo de rodízio como abaixo evidenciado. 


\section{DO SISTEMA DE RODÍZIO}

Cláusula Sétima - Os barcos cadastrados na COLÔNIA ficam autorizados a ingressar, em sistema de rodízio, com permanência de 10 (dez) dias nas águas do Parque Nacional do Cabo Orange para o exercício da pesca de pequeno porte, desde que os pescadores de pequeno porte já tenham firmado o termo de adesão acessório ao presente instrumento.

$\mathrm{S} 1^{\circ}$ - O rodízio será regulado pela COLÔNIA e fiscalizado pelo ICMBIO e IBAMA, não sendo permitida a presença concomitante de mais de 20 (vinte) barcos, a cada dez dias, nas águas do Parque Nacional do Cabo Orange, nem, em qualquer hipótese, de quaisquer outros pescadores de pequeno porte que não tenham firmado o termo de adesão acessório ao presente instrumento (p. 5);

O termo desponta como uma estratégia de manejo que atende uma população de forma compensatória. Assim, permite que os pescadores artesanais do Oiapoque possam reproduzir seus modos de vida de forma digna. Certamente o termo não figura como uma solução permanente, mas se mostra como um forte instrumento de garantia de direitos sociais e ambientais a uma população já bastante espoliada, mas atuante na busca de seus direitos, especialmente na manutenção de seu modo de vida.

\section{REFERÊNCIAS}

ABRAMOVAY, R. O futuro das regiões rurais. Porto Alegre: UFRGS, 2003.

ALMEIDA, A. W. B. de. Terras tradicionalmente ocupadas: terras de quilombo, terras indígenas, babaçuais livres, castanhais do povo, faxinais e fundos de pasto. 2 ed. Manaus: UFAM, 2008.

ALMEIDA, O.T., AMARAL, L., RIVERO, S., SILV, C. N. Caracterizacao do pescador e da frota pesqueira comercial de Manoel Urbano e Sena Madureira (AC) e Boca do Acre (AM). Belém, Novos Cadernos NAEA. Vol. 15, n. 1. p. 291-309, jan-jun 2012.

ALVES, J. R. P. (org). Manguezais: educar para proteger. Rio de Janeiro: FEMAR; SEMADS, 2001. 96 p.

ANTONAZ, D. Invenção e reprodução das reservas extrativistas na Amazônia: relação entre movimentos sociais, igrejas, ONGs e governos. In: GRIMBERG, M.; ALVAREZ, M. I. F.; ROSA, M. C. (ed.) Estado y movilización social: estudios etnográficos en Argentina y Brasil. Buenos Aires: Coedición FFyL-Antropofagia, 2009.

BARTHEM, R. B.; FABRÉ, N. N. Biologia e diversidade dos recursos pesqueiros da Amazônia. In: Ruffino, M. L. (Org.). A pesca e os recursos pesqueiros na Amazônia brasileira. Manaus: Provárzea, 2004. 
BEGOSSI, A. ; LEME, A. ; SEIXAS, C. S. ; CASTRO, F. de ; PEZZUTI, J. ; HANAZAKI, N. ; PERONI, N. ; SILVANO, R. A. M. Ecologia de Pescadores da Mata Atlântica e da Amazônia. São Paulo: Hucitec, 2004.

BRASIL. Constituição da República Federativa do Brasil. 1988. Brasília, DF.

CAVALCANTI, C. Uma tentativa de caracterização da economia ecológica. Ambiente e Sociedade, Campinas-SP, v. 7, n. 1, jun. 2004.

DIEGUES, A. C. S. Populações tradicionais em unidades de conservação. In: VIEIRA, P> F.; MAIMON, D. (Org.). As Ciências Sociais e a questão ambiental: rumo à interdisciplinaridade. Belém: NAEA/UFPA, 1993.

. O mito moderno da natureza intocada. 3. ed. São Paulo: Hucitec, 2001.

FRÉDOU, F. L.; ALMEIDA, O.; RIVERO, S.; MOURÃO, K.; BARBOSA, C.; THOMPSON, R. Aspectos econômicos da pesca industrial no Pará: entraves e perspectivas. Paper do NAEA, Belém, n. 265, mar. 2010.

FURTADO, Lourdes Gonçalvez; SILVEIRA, Isolda Maciel da; SANTANA, Graça (orgs). Reserva Extrativista Marinha Mãe Grande - Curuçá, Pará, Brasil: estudo etnológico e sociocultural. Belém: MPEG, 2012.

JERONIMO, Rosa Nadir Teixeira; GONCALVES, Teresinha Maria. O processo de apropriação do espaço e produção da subjetividade. Psic.: Teor. e Pesq., Brasília, v. 24, n. 2, jun. 2008. Disponível em <http://www.scielo.br/scielo.php?script=sci arttext\&pid=S0102-37722008000200009\&lng=pt\&nrm=iso $>$. Acesso em: 16 abr. 2014.

ICMBIO - INSTITUTO CHICO MENDES DE CONSERVAÇÃO DA BIODIVERSIDADE. Plano de Manejo Parque Nacional do Cabo Orange. Brasília, 2010. Disponível em: <http://www.icmbio.gov.br/portal/images/stories/imgs-unidadescoservacao/Encarte\%203\%20-\%20PNCO.pdf>. Acesso em: 15 abr. 2014.

ISAAC-NAHUM, V. J. Explotação e manejo dos recursos pesqueiros do litoral amazônico: um desafio para o futuro. Cienc. Cult. [online]. 2006, v. 58, n. 3, p. 33-36, 2006. ISSN 0009-6725.

MENEZES, M. P. M.; BERGER, U.; MEHLIG, U. Mangrove vegetation in Amazonia: a review of studies from the coast of Pará and Maranhão States, north Brazil. Acta Amazônica. v. 38, n. 3, p. 403-420, 2008. Disponível em: <http://www.scielo.br/scielo. php? script $=$ sci_arttext\&pid $=$ S0044-59672008000300004\&lng $=$ pt\&nrm $=$ iso $>$. Acesso em: 19 mar. 2014. http://dx.doi.org/10.1590/S0044-59672008000300004.

MORAES, A. de O., SCHOR, T. , ALVES-GOMES, J. A. - Relações de trabalho e transporte na pesca de bagres no rio Solimões - AM. Belém. Novos Cadernos NAEA. v. 13 , n. 1 , p. $155-170$, jul. 2010

MOURÃO, K. et al. Sistema de produção pesqueira pescada amarela - cynoscion acoupa lacèpede (1802): um estudo de caso no litoral nordeste do Pará - Brasil. Boletim do Instituto de Pesca, v. 35, n. 3, p. 497-511, 2009. Disponível em: <http://www.pesca. sp.gov.br/sumario35_3.php>. Acesso em: 02 jul. 2013. 
RAVENA-CAÑETE, T. Populações tradicionais e direito: da revisão a crítica de aplicabilidades e definições academicas/jurídicas/legais. 2012. 130 f. Dissertação (Mestrado em Direto) - Instituto de Ciências Jurídicas, Universidade Federal do Pará, Belém, 2012.

RUFFINO, M. L. Gestão do Uso dos Recursos Pesqueiros na Amazônia. Brasília: Ibama, 2005.

SCHAEFFER-NOVELLI, Y. Situação atual do grupo de ecossistemas: "Manguezal, Marisma e Apicum" incluindo os principais vetores de pressão e as perspectivas para sua conservação e usos sustentável. São Paulo, Brasil, 1989, p. 119. Disponível em: < http:// www.anp.gov.br/brnd/round5/round5/guias/perfuracao/5round/refere/manguezal_ marisma_apicum.pdf >. Acesso em: 02 dez. 2013.

SOUZA FILHO, P. W. M. Costa de Manguezais de Macromaré da Amazônia: cenários morfológicos, mapeamento e quantificação de áreas usando dados de sensores remotos. Revista Brasileira de Geofísica, v. 23, n. 4, p. 427- 435, 2005.

TOMLINSON, P. B. A botânica dos manguezais. Cambridge: Cambridge University Press, 1986.

VEIGA, J. E. Cidades imaginárias. 2. ed. Campinas-SP: Autores Associados, 2002. v. 1.198 p. 